\title{
Development and usage of Geosites: new results from research and conservation activities in the Piemonte Region (Italy)
}

\author{
Luca GHIRALDI $^{* *}$, Paola CORATZA ${ }^{1}$, Ermanno DE BIAGGI ${ }^{2}$, Marco GIARDINO ${ }^{3}$, \\ Mauro MARCHETTI ${ }^{1}$ \& Luigi PEROTTI ${ }^{3}$ \\ ${ }^{1}$ Department of Earth Sciences, University of Modena and Reggio Emilia, Largo Sant' Eufemia 19, 41100 Modena, Italy \\ ${ }^{2}$ Torino Natural Science Museum, Via Giovanni Giolitti 36, 10123 Torino, Italy \\ ${ }^{3}$ GeoSITlab, Department of Earth Sciences, University of Torino, Via Valperga Caluso 35, 10125 Torino, Italy
}

Received March 2009; accepted June 2009

Available online September 2009

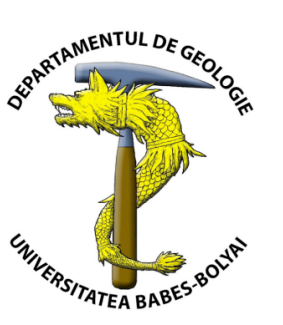

\begin{abstract}
This paper describes a series of activities carried out by public institutions, whose aim is to identify possible ways of acquiring knowledge and of allowing enjoyment of the Piemonte Region's geological heritage. The activities concern the inventory, the evaluation, the storage and the publication of information, both alphanumerical and geographical, in relation to geosites. A database accessible directly from Web and a Web-GIS application has been developed in order to supply valuable and comprehensive instruments for both, representing the results of research and promoting the knowledge of the geological heritage to a large number of people.
\end{abstract}

Key words: geodiversity, geosite, inventory, Web-GIS, Italy

\section{INTRODUCTION}

Among the Italian regions, Piemonte is remarkable because of its variety of landscapes and environments including mountains, hills and plains. Similar to other Italian regions, research and conservation activities for recognizing, describing and popularizing sites of geological and geomorphologic interest also started in Piemonte.

The first initiative was the publication of the "Carta Geomorfologica degli Elementi di Interesse Paesaggistico del Parco Nazionale del Gran Paradiso", accompanied by descriptive cards of selected geosites (Giardino and Mortara, 2001). A remarkable impulse was given by the publication of two popular books concerning the exploitation of geomorphological sites in the Torino Province (Giardino and Mortara, 2004). At the end of 2004 the cooperation between the managing authority of Asti Province Natural Parks and the Department of Earth Science of Torino University, allowed the inventory of 219 geosites located in the Asti Province and the Torino Hill (Biancotti, et al., 2004). More research has been carried out by student thesis and municipality's autonomous initiative in several areas of our region.

In order to gather scattered information concerning the geological heritage of the Piemonte region, an agreement between the University of Torino (Earth Science Department) and the Natural Science Museum of Torino was signed. The aim of this cooperation is to identify possible ways of acquiring knowledge and of allowing enjoyment of the Region's geological heritage. This can be *Correspondence: L. Ghiraldi (luca.ghiraldi@gmail.com) achieved not only by means of inventory and assessment of the most important sites of geological interest, but also by programs of usage and popularization. The complex earth system terminology has to be translated into a simple language, allowing a knowledgeable approach for a general public and professionals involved in educational activities.

\section{INVENTORY AND EVALUATION OF GEOSITES IN THE PIEMONTE REGION}

In order to define the state of the art in geosite studies in the Piemonte Region and to identify the geoconservation projects developed by public or private institutions, a bibliographic research and field data collection was performed. At the end of this reconnaissance phase, more than 300 sites with a geological interest scattered all around the Region were identified. Most of these descriptions are not exhaustive from a scientific point of view, but they inform about location and general characteristics of landforms and processes that could be classified as geosites.

A lot of data coming from different sources were homogenized and organized by means of an inventory card purposely set-up. It holds all the information requested for Geosites by the Italian National Geological Survey, it also includes additional information allowing evaluating geosites from scientific, aesthetic, accessibility, cultural/historical and ecological point of view.

Part 1 of the card deals with the collection of general data, including location, description, essential features 
(forms and dimension, property, planning restrictions, soil use, lithology, chronostratigraphy).

Parts 2 and 3 of the card, concern the evaluation process to determine intrinsic value of geosites. The intrinsic value, according with Reynard et al. (2007), is defined by comparison of scientific value of geosites against their additional values, which include ecological, culturalhistorical, accessibility and aesthetic assessment of the geosites. Criteria used to assess the "scientific value" reflect those suggested by Grandgirard (1999): integrity, representativeness, rareness and paleogeographical value; the terms are defined closer in Table 1. The criterion to evaluate each category included in the "additional value" is described in more detail in Table 2. The "ecological value" takes into account the importance of geosite for the development of a particular ecosystem. The assessment of "aesthetic or scenic value" is very subjective and especially depends on the spectacular and intrinsic aspect of a geosite. The "cultural value" is obtained combining different characters, it takes into account religious, historical, artistic or literary importance. The "accessibility value" combined with geological hazards should be also taken into account when a geo-itinerary are proposed.

Table 1. Criteria used for the assessment of "Scientific Value".

\begin{tabular}{cc}
\hline Criterion & Evaluation \\
\hline Integrity & $\begin{array}{c}\text { State of conservation of the site. Bad } \\
\text { conservation may be due to natural or } \\
\text { human factors }\end{array}$ \\
\hline Representativeness & $\begin{array}{c}\text { Concerns the site exemplarity. Used with } \\
\text { respect to a reference space (e.g. region, } \\
\text { community, country). }\end{array}$ \\
\hline Rareness & $\begin{array}{c}\text { Concerns the rarity of the site with respect } \\
\text { to a reference space. The criterion serves to } \\
\text { identify exceptional landforms in a area. }\end{array}$ \\
\hline Paleogeographical value & Importance of the site for Earth or climate \\
history.
\end{tabular}

Table 2. Criteria used for the assessment of "Additional value".

\begin{tabular}{cc}
\hline Additional Value & Criteria \\
\hline Ecological value & $\begin{array}{c}\text { Concerns the ecological importance of the } \\
\text { site and if the site is protected by national } \\
\text { or regional laws. }\end{array}$ \\
\hline Aesthetic value & $\begin{array}{c}\text { Concerns the scenography of the site, in } \\
\text { terms of contrast with surrounding } \\
\text { landscape, number of view point and } \\
\text { development and structuring of the form. }\end{array}$ \\
Cultural value & $\begin{array}{c}\text { Concerns the importance of different } \\
\text { aspects: religious, historical, artistic and } \\
\text { literature. Furthermore takes into account if } \\
\text { the site is important for the local }\end{array}$ \\
\hline Accessibility value & $\begin{array}{c}\text { Concerns the accessibility to the site, takes } \\
\text { into account the road conditions, difficulty } \\
\text { of the path, the distance and time to cover } \\
\text { by foot or the distance from facilities. }\end{array}$ \\
\hline
\end{tabular}

For each criterion relative to scientific and additional categories, five possible values (from 0 to 1) may be assigned in order to obtain a table with a score for each geosite. Geosites that scored overall highest have been selected for exploitation strategies; the same is true for those with high scientific value. Contrary, those sites that scored overall lowest or with a poor scientific value, have been discarded.

Data collected from bibliographic research and terrain surveys have been organized into a relational database (MySQL Community Edition released under GNU General Public licence). Data information stored into the database, Studia UBB, Geologia, 2009, 54 (2), 23 - 26 may be retrieved from the Web through PHP scripting language, which has full support for communicating with MySQL Database (Figs. $1 \mathrm{a}, \mathrm{b}$ ).

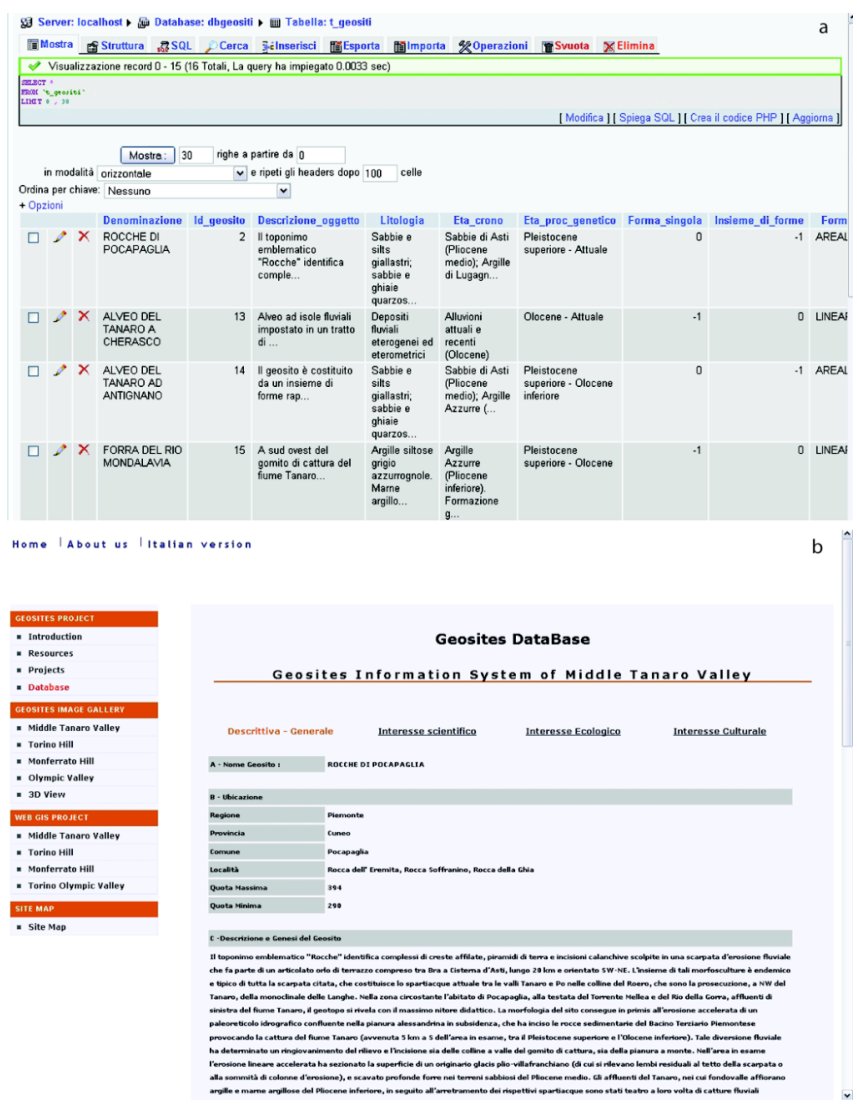

Fig 1. a) PHP MyAdmin a graphical interface to manage data stored in MySQL DB; b) Web interface implemented using HTML and PHP allowing to query and navigate database.

\section{GIS PROJECT AND MAPPING}

By means of GIS software, it is possible to correlate and combine a lot of layer information representing them at different scale, by using zoom tools; furthermore, with query tools it is easy to retrieve geo-referenced "objects" on the map and to access the attributes associated with it. The scale problem in GIS environment it is less important with respect to a traditional map; still, according to Carton et al. (2005), the accuracy of representation depends on the scale at which the data were mapped. In our case studies, geosites have been represented by dots if the map is at the regional scale. In large scale mapping, geosites and in particular those of geomorphologic importance are represented by means of linear, point-like or polygon symbols in order to produce a simplified geomorphologic map, where only the symbols showing the form making up geomorphologic sites will be depicted, whereas all the other elements of the landscape will be omitted.

Working on a small area, makes the production of large scale thematic maps, easier. In this kind of representation besides geological features, there is information on ecological, historical, religious and cultural aspects, giving additional value to the geological object. Furthermore, using photogrammetric technique and digital terrain model (DTM) with a good resolution, it is possible to construct shaded models and 3D bird's-eye views, helpful to facilitate the comprehension of the forms of the present-day landscape (Figs. 2 a-c). 

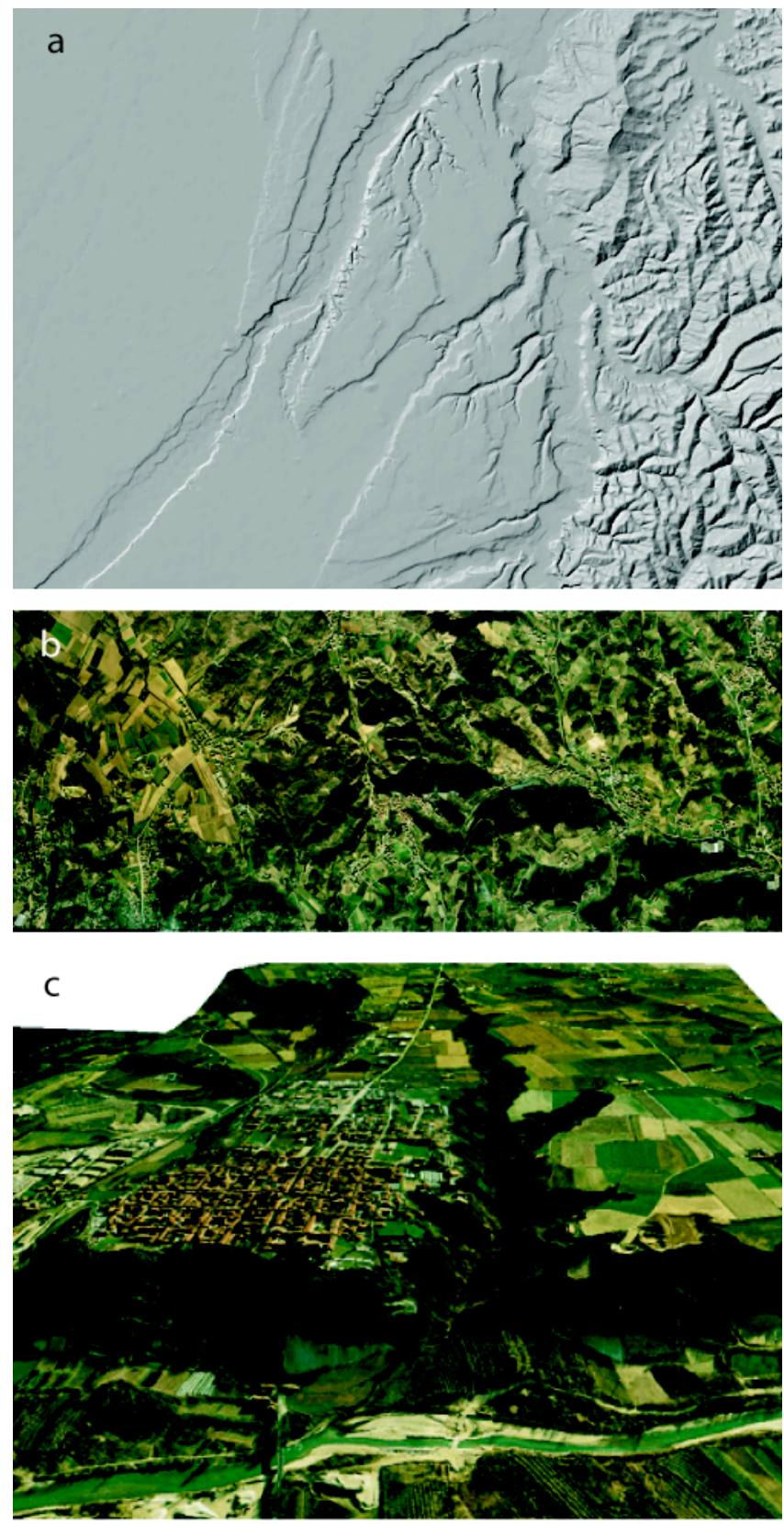

Fig. 2. a) Hillshade model derived from DEM (10 $\mathrm{m}$ resolution); b) Mosaic of aerial photographs obtained using photogrammetry technique; c) $3 D$ bird's eye view obtained combining ortho-mosaic and DEM.

After collection of all the information, it is possible to conceive specific itineraries not only for people involved in the field of geosciences, but also for a general public and teachers. Following the approach proposed by Giardino and Mortara (2004) to each itinerary a card containing pictures and descriptions structured in four main sections, was assigned:

- In the first one, a general outline of the site, with a description of the geomorphologic and geological features in relation to their forming processes, is presented;

- In the second one, there is a set of pictures, stratigraphic sections, $3 \mathrm{D}$ views and texts useful to understand the geomorphologic and geological evolution of the geosite;

- In the third section the reader is informed on possible hazards and their potential risks;

- The last section contains curiosities, legends, and cultural or ecological notes concerning the geosite.

\section{WEB-GIS APPLICATION}

GIS applications whose functionality is combined with Internet technology, allowing the publication of cartographical data integrated with other information, including images, descriptive cards and virtual bird's-eye views. They can be valuable and comprehensive instruments to represent results of research to the general public. In order to promote the knowledge and the usage of the geosites, to a large number of people, a Web-GIS application, based on MapServer (www.mapserver.org) and PMapper (www.pmapper.net), has been developed (Fig. 3).

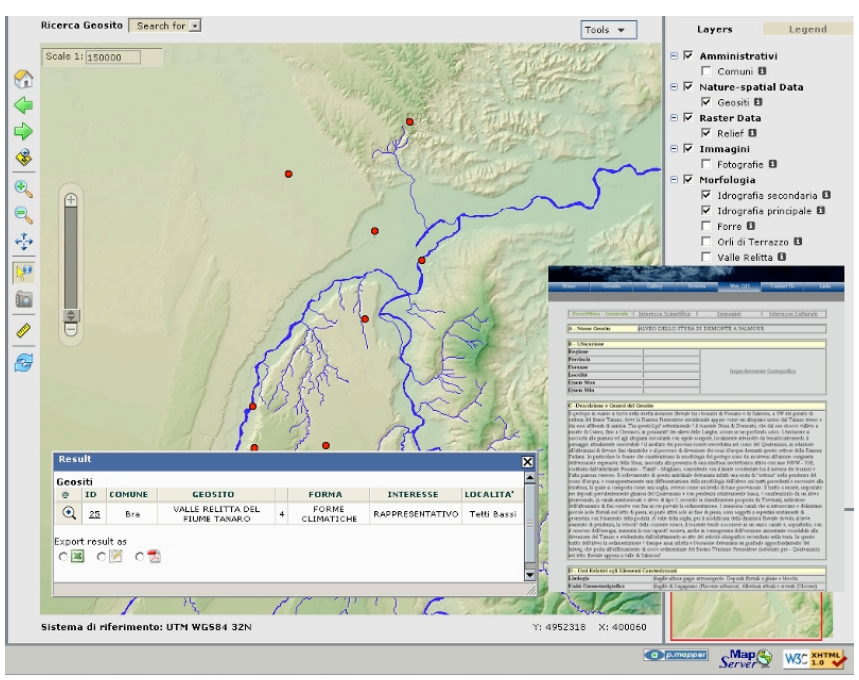

Fig. 3. Web-Gis application based on MapServer and PMapper. Hyperlink function present in the attribute table allows to recover many types of information including those stored in MySQL Db.

\section{BIBLIOGRAPHIC DATABASE}

Bibliographic data concerning general aspects of geosites have been organized using specific software: EndNote (www.endnote.com), useful to manage references, images and PDFs. Once the data are stored, it is not only possible to make the "usual" queries that are expected to be performed on a computerized library (e.g., by author, year, subject and so on) but also a digital copy of the original work, if available, can be recalled and looked up simply clicking on a link.

These instruments, if periodically updated, allow defining the state of the art concerning several aspects on geosite's studies both at international level and at regional level.

\section{CONCLUSIONS}

Preliminary results from these activities can be considered as fundamental steps developing a new awareness of the importance of geosites for a wide public. For this reasons large efforts have been made translating the complex earth system in a simple language, but at the same time preserving scientific methods and approaches. In order to improve results and applications of the research program, the next steps of activities will be:

- A further data collection of new features and updates of previously collected ones;

- Implementation of new functions in the system; 
- Completing the descriptive cards with information of geological or geomorphologic aspects;

- Proposal of new itineraries with maps and field guides.

At the moment of this paper the service is just a prototype in a early stage and is not available yet, it should be on-line in a few months at www.geositlab.unito.it. All the activities will be carried out in different parts of the Piemonte Region and will be developed in agreement with local institutions.

\section{R E F E R E N C E S}

Biancotti, A., Bortolami, G., Pavia, G., Ajassa, R., Cavagna, S., Clari, P.A., Costamagna, A., Damarco, P., De Luca, D., Dela Pierre, F., De Petrini, G., Giardino, M., Masciocco, L., Maia, F., Martire, L., Martinetto, E., Motta, M., Ricci, B. \& Rossetti, P.G. 2004, Censimento dei Geositi del Settore Regionale Collina di Torino e Monferrato. Regione Piemonte, Quaderno Scientifico 5, $146 \mathrm{p}$.
Carton, A., Coratza, P. \& Marchetti, M. 2005, Guidelines for geomorphological sites mapping: examples from Italy. Géomorphologie: relief, processus, environment, 3: 209-218.

Giardino, M., Mortara, G. 2001, Carta geomorfologica degli elementi di interesse paesaggistico del Parco Nazionale del Gran Paradiso. Revue Valdotaine d'Histoire Naturelle, 53: 5-20.

Giardino, M., Mortara, G. 2004, I geositi nel paesaggio della Provincia di Torino. Pubblicazione del Servizio Difesa del Suolo della Provincia di Torino, v. I, 116 p.

Grandgirard, V. 1999, L'evaluation des geotopes. Geologia Insubrica, 4: 59-66.

Reynard, E., Fontana, G., Kozlik, L. \& Scapozza, C. 2007, A Method for assessing "Scientific" and "Additional values" of geomorphosites. Geographica Helvetica Jg. 62 (3): 148-158.

EndNote: www.endnote.com

MapServer: www.mapserver.org

PMapper: www.pmapper.net 